\title{
THE VENTRAL PALLIDAL PROJECTION TO THE MEDIODORSAL THALAMUS: A STUDY WITH FLUORESCENT RETROGRADE TRACERS AND IMMUNOHISTOFLUORESCENCE ${ }^{1}$
}

\author{
W. SCOTT YOUNG, III,* GEORGE F. ALHEID, $\ddagger$ AND LENNART HEIMER*,2 \\ Departments of *Neurology and $\ddagger$ Behavioral Medicine and Psychiatry at the Clinical Neurosciences Center, University of \\ Virginia School of Medicine, Charlottesville, Virginia 22908
}

Received October 19, 1983; Revised December 5, 1983; Accepted January 13, 1984

\begin{abstract}
We have examined rat basal forebrain projections to the mediodorsal thalamic nucleus (MD) by making injections of retrogradely transported fluorescent tracers into the MD. Additionally, in some animals, we also stained sections for glutamate decarboxylase (GAD) by the indirect fluorescent antibody technique.

Our results demonstrate that the following basal forebrain areas project to the MD: lateral orbital cortex, agranular insular cortex superficial to claustrum, primary olfactory cortex, diagonal band nuclei, ventral pallidum, and amygdala. A large number of labeled cells are present in the olfactory tubercle, and these cells are almost without exception located in dense GAD-positive ventral pallidal areas rather than in striatal regions of the tubercle. This ventral pallidal projection to the MD strengthens the concept of a ventral striatal-pallidal system in parallel to the classic striatal-pallidal system which projects to the ventral thalamus. These results are also discussed in relationship to the olfactory system.
\end{abstract}

The afferent forebrain connections of the mediodorsal thalamic nucleus (MD) have been studied by methods of degeneration (Guillery, 1959; Nauta, 1961; Powell et al., 1965; Leonard, 1969; Leonard and Scott, 1971; Scott and Leonard, 1971; Heimer, 1972), anterograde transport (Krettek and Price, 1974, 1977b; Akert and HartmannVon Monakow, 1980; Benjamin et al., 1982; Haber et al., 1982; Price and Slotnick, 1983), and horseradish peroxidase retrograde transport (Siegel et al., 1977; Sapawi and Divac, 1978; Benjamin et al., 1982; Groenewegen and Nauta, 1982; Markowitsch et al., 1982; Inagaki et al., 1983; Price and Slotnick, 1983). The olfactory tubercle contributes some of these afferents (Scott and Leonard, 1971; Heimer, 1972; Siegel et al., 1977; Benjamin et al., 1982; Price and Slotnick, 1983), and the suggestion has been made that the olfactory tubercle projection to MD may form part of a ventral pallidal projection which parallels the classical pallidal outflow to the ventral anterior and ventral lateral nuclei of the thalamus (Heimer, 1978; Goldschmidt and Heimer, 1980). In fact,

${ }^{1}$ This work was supported by National Institutes of Health Grant RNS1774303. We wish to express our gratitude for the helpful discussions with Dr. Laszlo Zaborszky and for the excellent assistance of Venessa Alones, Shareen Guilford, Cindy Brashear, and Rose Powell. We gratefully acknowledge the gift of GAD antibody from Drs. D. E. Schmechel and W. H. Oertel.

${ }^{2}$ To whom correspondence should be addressed. several histochemical studies support the concept that part of the olfactory tubercle consists of a ventral extension of the globus pallidus (Switzer and Hill, 1979; Haber and Nauta, 1981, 1983; Haber et al., 1982; Switzer et al., 1982; Zaborsky et al., 1982). In an attempt to investigate this hypothesis further, we have injected retrograde fluorescent tracers into the MD and have examined the distribution of MD-projecting neurons relative to simultaneous immunostaining for L-glutamate-1-decarboxylase (GAD; EC 4.1.1.15) (McLaughlin et al., 1974; Oertel et al., 1981, 1982; Wu et al., 1982). GAD is the $\gamma$ aminobutyric acid (GABA)-synthesizing enzyme and is found in high concentrations in the dorsal and ventral pallidum (Fonnum et al., 1978; Walaas and Fonnum, 1979; Perez de la Mora et al., 1981; Zaborsky et al., 1982; Fallon et al., 1983). GABA is thought to be a transmitter for both pallidal efferents and afferents, and in preliminary experiments we observed that the ventral pallidum is characterized by a dense plexus of GAD terminal staining. GAD terminal staining in the MD also corresponded to the pattern of terminal degeneration seen after superficial olfactory tubercle lesions. Therefore, double labeling of MD-projecting neurons was also attempted in colchicine-treated rats.

\section{Materials and Methods}

Subjects. A total of 53 male Sprague-Dawley rats, weighing 110 to $200 \mathrm{gm}$, was used. 
Fluorescent tracers. Granular blue (GB) and fast blue (FB) (Dr. Illing, KG. Gross-Umstadt, West Germany) were injected as a 5 to $10 \%$ suspension in $2 \%$ dimethylsulfoxide (DMSO). GB was injected into the MD of five rats, and FB was used for $28 \mathrm{MD}$ injections and eight control injections. Survival times after FB and GB injections ranged between 1 and 2 weeks.

We also attempted retrograde labeling with disodium SITS (4-acetamino, 4-isocyanostilbene-2,2' -disulfonic acid) (Schmued and Swanson, 1982). However, in preliminary experiments we determined that this commercially available product (Chemical Dynamics, South Plainfield, $\mathrm{NJ}$ ) did not transport in distilled water (with or without DMSO). The structure of this yellow compound was identified as disodium SITS by neutral xenon beam mass spectroscopy. Dr. Swanson kindly supplied some red "SITS" (R-SITS) which did transport, but we were unable to elucidate its structure. R-SITS (5\% in $2 \%$ DMSO) was injected into eight rats. Four rats received MD placements, and the remaining four rats received control placements. Rats injected with R-SITS were sacrificed 2 to 4 weeks after surgery.

Finally, two of the rats with FB injections into the MD received pressure injections of $300 \mathrm{nl}$ of Nuclear yellow (NY, $1 \%$ in distilled water; courtesy of Prof. O. Dann) into the ipsilateral olfactory bulb 6 days after the FB injections and 20 to $24 \mathrm{hr}$ prior to sacrifice.

Surgery. Stereotaxic surgery was performed using Chloropent $(3.3 \mathrm{ml} / \mathrm{kg}$; Fort Dodge Laboratories, Fort Dodge, IA) for general anesthesia. In 46 rats, 25 to $60 \mathrm{nl}$ of tracer were pressure injected over $10 \mathrm{~min}$ using a $1-\mu \mathrm{l}$ Hamilton syringe with a glass micropipette cemented to the tip. In the remaining seven rats, tracers were depositcd by micropipette implants to avoid tracer deposits in the pipette track (Alheid and Carlsen, 1982).

All MD placements used the following coordinates: 2.2 $\mathrm{mm}$ behind bregma, $0.5 \mathrm{~mm}$ lateral to the superior sagittal sinus, and $5.2 \mathrm{~mm}$ below dura, with the tooth and ear bars at the same height. For 11 FB and two R-SITS injections, the MD was injected from the opposite side at a $26^{\circ}$ angle above the horizontal. The pipette track passed through the lateral portions of the contralateral hippocampus and stria medullaris, as well as the contralateral MD and paraventricular nucleus. Pipette implants were made in the MD for five FB and two R-SITS placements.

Control injections of FB (eight animals) or R-SITS (four animals) were made in the stria medullaris-habenular complex area and medial hippocampus. These injections did not involve the MD.

To improve immunostaining of cells, 14 rats with MD injections also received a total of 50 or $100 \mu \mathrm{g}$ of colchicine intraventricularly in $25 \mu \mathrm{l}$ of $0.1 \mathrm{M}$ phosphatebuffered saline (PBS), $\mathrm{pH}$ 7.4, ipsilaterally, contralaterally, or bilaterally, $48 \mathrm{hr}$ prior to sacrifice.

Immunohistochemistry and cytochemistry. Sections for immunohistofluorescence were placed in $1 \%$ polyvinyl pyrolidone and $40 \%$ ethylene glycol in $0.1 \mathrm{M}$ potassium acetate, $\mathrm{pH} 6.5$, until processed. They were then washed in $0.1 \mathrm{M}$ PBS and placed in PBS containing $0.05 \%$ sodium azide, $0.25 \%$ carrageenan (type IV, Sigma Chemical Co., St. Louis, MO), 0.3\% Triton X-100, and a 1:2000 dilution of antisera against GAD (courtesy of Drs. D. E.
Schmechel and W. H. Oertel). These incubations were performed at $4^{\circ} \mathrm{C}$ overnight, and they were washed with PBS for $5 \mathrm{~min}$ thrice before a 45 -min incubation in antiIgG antisera conjugated with fluorescein isothiocyanate (FITC) (dilution 1:100 to 150; Miles Biochemicals, Elkhart, IN) in PBS at room temperature. The sections were then washed three times with PBS, mounted, and coverslipped with a $0.1 \mathrm{M}$ lithium carbonate-glycerol solution, $\mathrm{pH}$ 8.5.

As a control for specificity of immunostaining, goat serum was substituted for the primary GAD antiserum, and this resulted in loss of immunostaining. In addition, the GAD antiserum has been previously characterized (Oertel et al., 1981, 1982). Some sections were counterstained for $1 \mathrm{~min}$ with $2.5 \times 10^{-7} \mathrm{M}$ ethidium bromide (Sigma Chemical Co.) before the last wash (Schmued et al., 1982). This provided a convenient counterstain which appeared orange on FITC fluorescence (Fig. 6) or red with a 546/590 nm exciter/barrier filter set. The sections were viewed on a Zeiss epifluorescent microscope with exciter/barrier filter set $365 / 418 \mathrm{~nm}$ for $\mathrm{GB}, \mathrm{FB}$, RSITS, and NY and with filter set $450-490 / 520 \mathrm{~nm}$ for FITC.

Counterstaining for $\mathrm{AChE}$ was performed in rat 83076 . Fifteen-micrometer sections were thaw-mounted onto pig-gelled slides. Photographs were taken of tracer-positive (TP) cells, and then the sections were processed by the method of Hardy et al. (1976) for AChE. Pictures of these stained sections were then examined for doublelabeled cells.

\section{Results}

Technical considerations. The fluorescent tracer injections were generally located in the central and medial portions of the MD. These areas were targeted because lesioning of the olfactory tubercle results in terminal degeneration within the central portion of the MD (Heimer, 1972). There was some variation in the dorsalventral placement of the tracers with occasional but minimal involvement of the habenular complex and stria medullaris. FB and GB pressure injections covered approximately equal areas, while the micropipette implants resulted in smaller injection sites without tracer deposit along the pipette track. R-SITS seems to cause a peripheral zone of neuronal cell loss with gliosis around a small central area of necrosis (Fig. 1), whereas FB and GB cause a slightly larger area of necrosis (Fig. 2). The halos of the R-SITS injections seem larger than those produced by FB or GB. When R-SITS was injected into the corpus callosi of two animals, no uptake and transport by commissural fibers occurred.

All three tracers deposited in the MD demonstrate identical distributions of projecting cells. FB most clearly demonstrates both cell bodies and proximal dendrites (Fig. 3). Indeed, even the axons passing through the inferior thalamic peduncle are evident as pale "brush strokes." R-SITS appears as bright bluish-white granules within cell bodies (Fig. 4) and is rather impervious to diffusion during immunohistochemical staining, whereas the FB and GB exhibit considerable leaching. Interestingly, R-SITS-containing cells show a regional variation in sensitivity to colchicine. In the olfactory tubercle and diagonal band many fewer well defined tracer-positive 

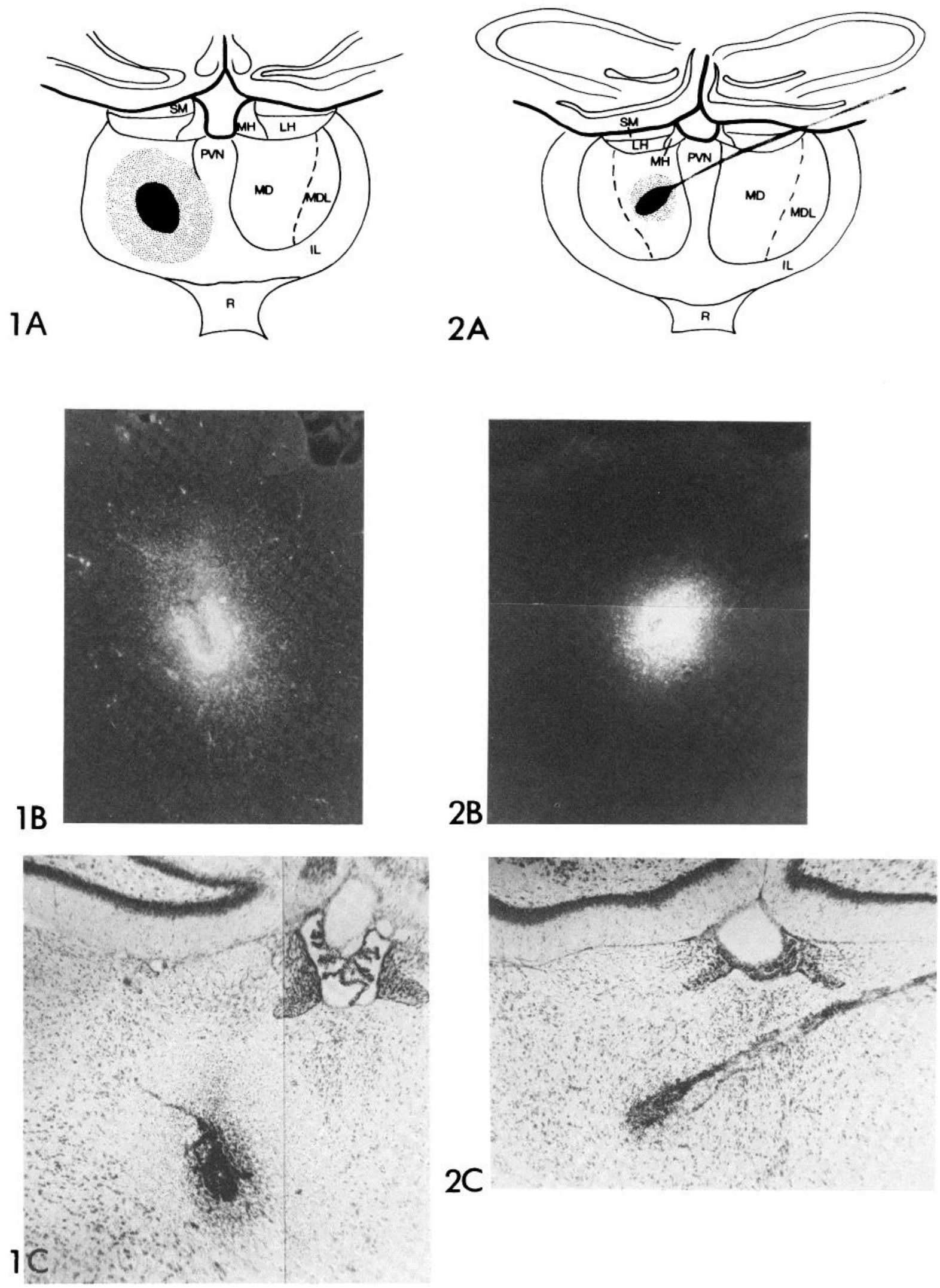

Figure $1 .^{3}$ Schematic illustration $(A)$ and fluorescent $(B)$ and brightfield $(C)$ photomicrographs of R-SITS injection into MD by dorsal approach in rat 83035 . Magnification $\times 30$.

Figure 2. Schematic illustration $(A)$ and fluorescent $(B)$ and brightfield $(C)$ photomicrographs of FB injection into MD by $26^{\circ}$ angular approach from opposite side in rat 83076. Magnification $\times 30$. 

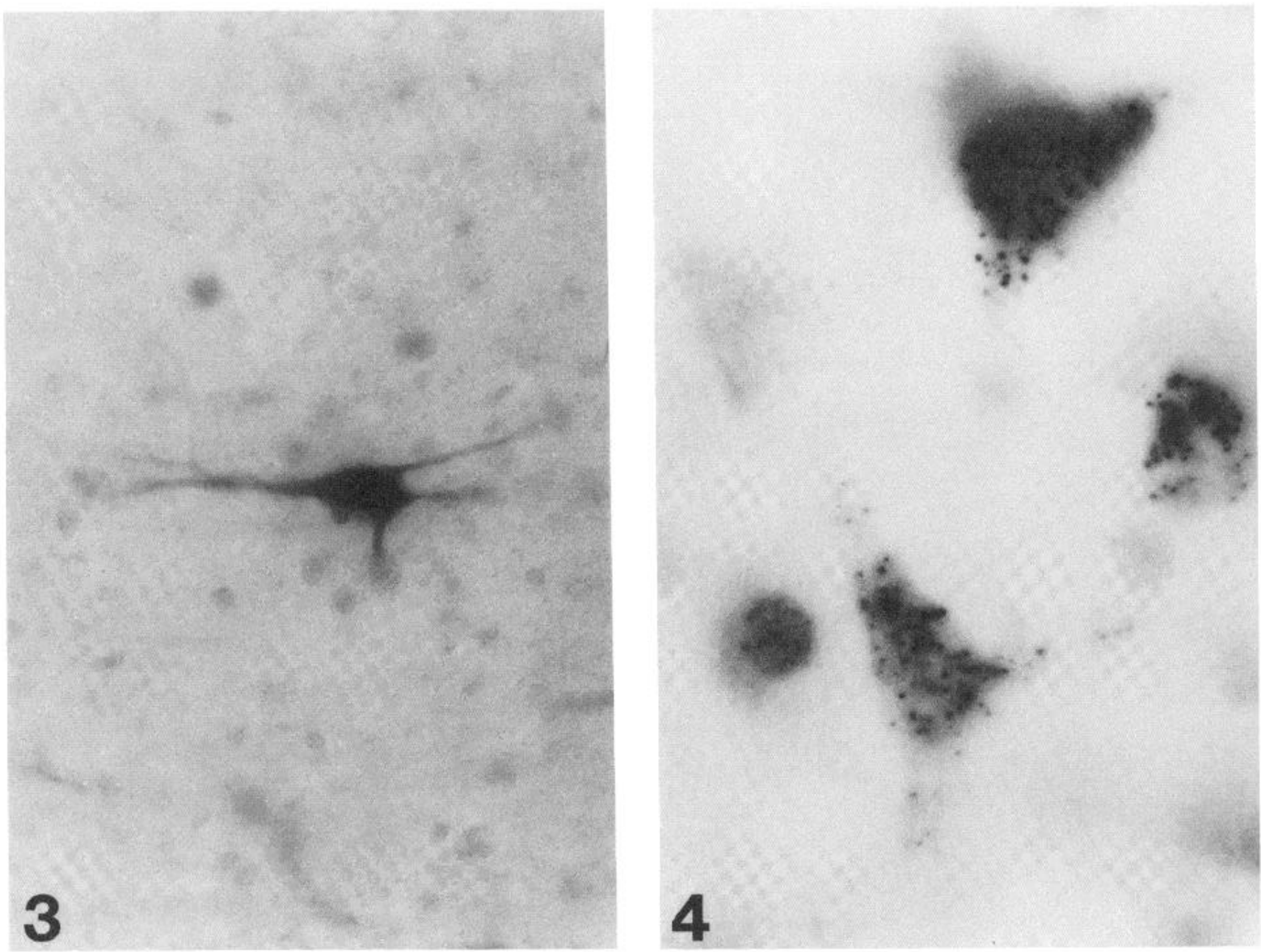

Figure 3. Fluorescent photomicrograph (negative image) of an FB retrogradely labeled cell from the MD in the POC. Magnification $\times 910$.

Figure 4. Fluorescent photomicrograph (negative image) of several R-SITS retrogradely labeled cells from the MD in the ventral pallidum. Magnification $\times 910$.

somata are seen after colchicine treatment. Instead, previously unobserved fibers containing typical fluorescent granules are present in the same area. In contrast, TP cells in the neocortex and the prepiriform cortex, i.e., the primary olfactory cortex, for example, are much less or not affected. Labeling of cells by FB and GB is less affected by colchicine treatment. A characteristic feature of R-SITS is its affinity for capillary endothelial cells. However, this staining is homogeneous and easily differentiated from the granular neuronal labeling.

Immunohistochemical delineation of ventral pallidum. The striato-pallidal projection system represents one of

\footnotetext{
${ }^{3}$ Abbreviations used in the figures are as follows: $A C$, anterior commissure; $A c c$, accumbens nucleus; $B S T$, bed nucleus of stria terminalis; $C$, claustrum; $C C$, corpus callosum; $D M S O$, dimethylsulfoxide; $E n d$, endopyriform nucleus; $E t B$, ethidium bromide; $F B$, fast blue; FITC, fluorescein isothiocyanate; GABA, $\gamma$-aminobutyric acid; GAD, glutamate decarboxylase; $G B$, granular blue; $I C$, island of Calleja; $I L$, intralaminar nucleus; $L H$, lateral habenula; $L O T$, lateral olfactory tract; $M D$, mediodorsal thalamic nucleus; $M D L$, mediodorsal thalamic nucleus, lateral part; $M H$, medial habenula; $N H D B$, diagonal band nucleus, horizontal limb; $N V D B$, diagonal band nucleus, vertical limb; $N Y$, nuclear yellow; $O T$, olfactory tubercle; $P O C$, primary olfactory nucleus; $P V N$, paraventricular nucleus; $R$, rhomboid nucleus; $R$-SITS, retrograde tracer, unknown structure; $S$, striatum; $S M$, stria medullaris; $T P$, tracer-positive; $V P$, ventral pallidum; $V S$, ventral striatum.
}

the best known GABAergic pathways in the brain (Fonnum et al., 1974, 1978; Nagy et al., 1978), and it is estimated that about $90 \%$ of the terminals on the dendrites and somata of typical pallidal cells contain GAD (Ribak et al., 1979; Ribak, 1981). This, and the fact that globus pallidus cells also contain $\mathrm{GAD}$, is consistent with the intense immunoreactivity of the pallidum in sections stained for GAD. The intense GAD-staining puncta in the globus pallidus provide an easily recognizable pattern which can be readily distinguished from the less intense staining in nearby striatal areas. Some of the most characteristic pallidal features in immunohistochemically stained sections for GAD are large transversely or longitudinally cut profiles lined by GAD-like immunoreactivity. There can be little doubt that such profiles represent dendrites of typical pallidal neurons covered by GAD-positive terminals (Ribak et al., 1979; Ribak 1981). Studies in our laboratory indicate a close correspondence between substance $\mathrm{P}$, enkephalin, and GAD-like immunoreactivity in the pallidal areas (Zaborszky et al., 1982; L. Zaborszky, personal communication), and in the present paper we have used GAD as an effective marker for the ventral pallidum.

The distribution of GAD immunoreactivity in the olfactory tubercle and adjacent areas is briefly described here in order to define the ventral pallidum and its 

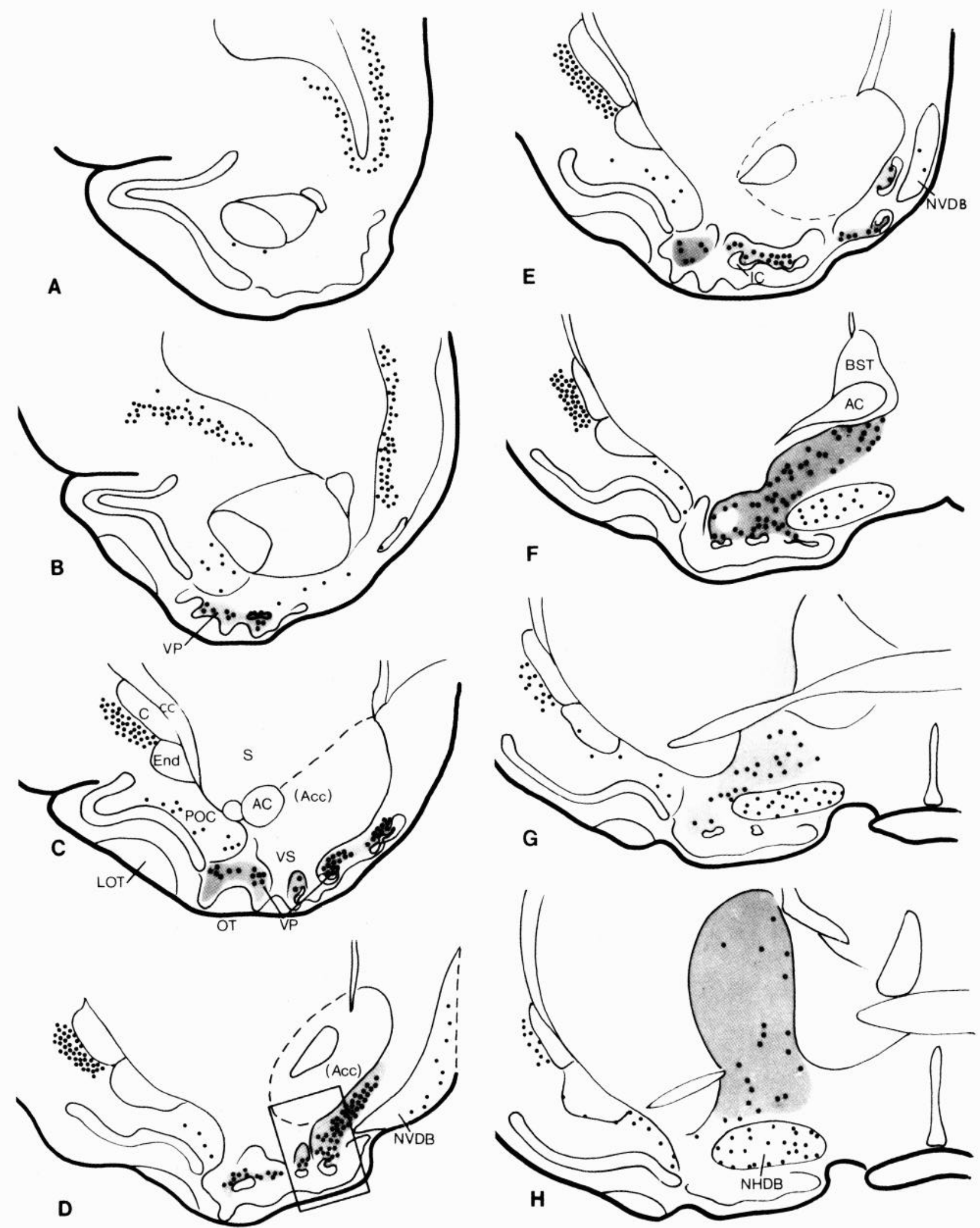

Figure 5. Diagrams of coronal sections from rat 83035 illustrating distribution of TP cells in relation to the areas of heavy GAD staining (pallidal areas). The area boxed in $D$ is shown in Figure 6 .

relationship to MD-projecting cells (Figs. 5 and 6). Heavy GAD staining first appears at the rostral tip of the olfactory tubercle as collections of immunoreactive processes in the polymorph layer projecting into the invagi- nations of the pyramidal cell layer. Slightly more caudally, this dense staining is located more dorsally in patches in the polymorph layer also with "fingers" extending into the pyramidal cell invaginations and into 

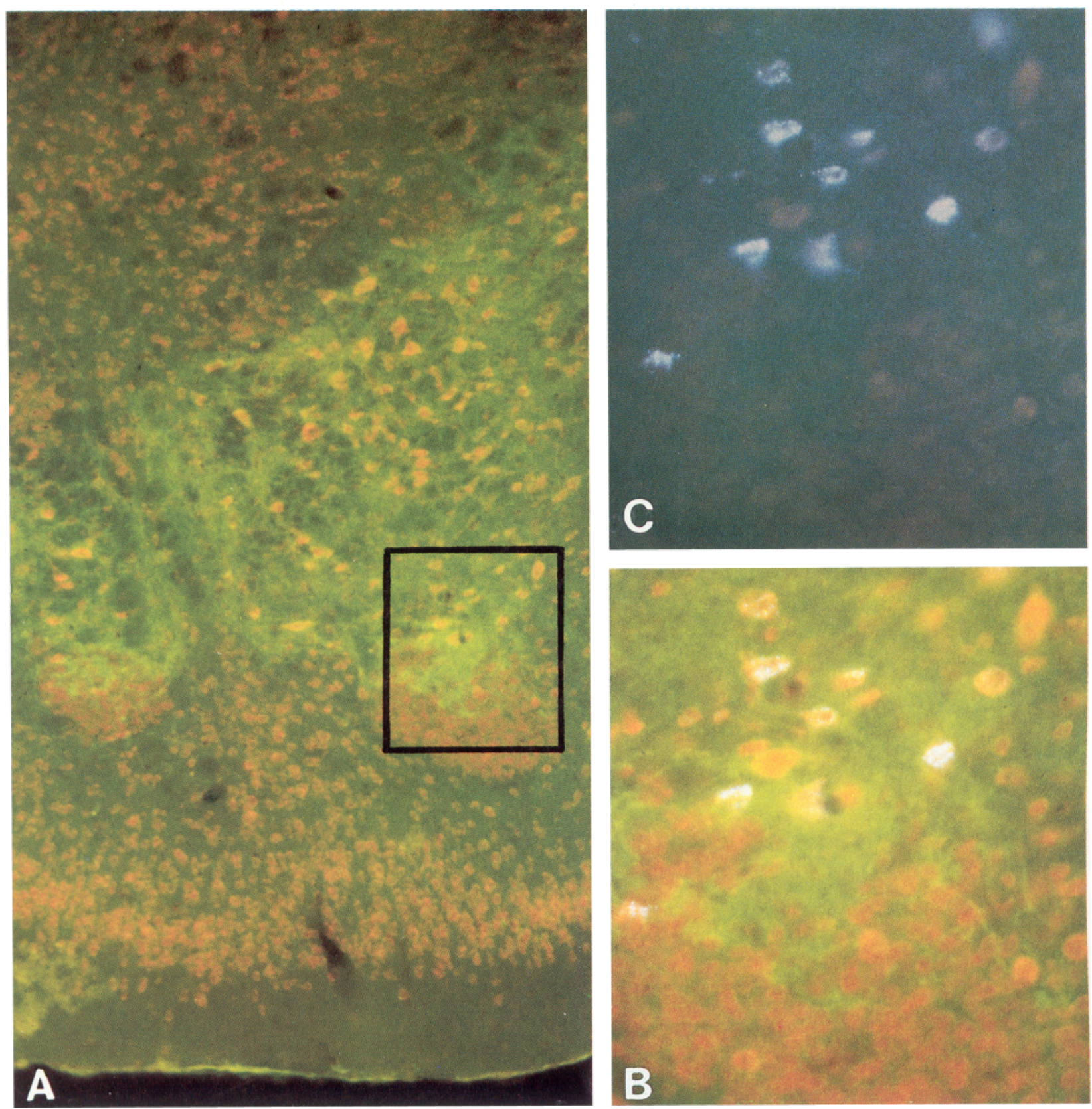

Figure 6. Photomicrograph enlargements of the olfactory tubercle shown in the box in Figure 5D. The EtB-counterstained cells appear orange and the GAD FITC green. In $A$ (magnification $\times 180$ ), two islands of Calleja are shown in relation to the GAD immunoreactivity. $B$ is a double image showing the retrogradely labeled R-SITS cells in proximity to the island on the right in $A$. The same R-SITS cells in $B$ are shown with only faint EtB counterstaining in $C$. Magnification: $B$ and $C, \times 450$.

hiluses of the islands of Calleja. Some islands of Calleja are heavily capped by the GAD processes (Fig. 6). This ventral pallidal staining ends abruptly at the border of the primary olfactory cortex (POC). Caudally, the dense GAD patches are frequently interconnected by overlapping cell processes or coalesce to form a band across the width of the tubercle and extend medially up to the insula Calleja magna. When the vertical limb of the diagonal band appears, the ventral pallidal GAD staining forms layers adjacent to the diagonal band's lateral aspect and fades dorsally at about the level of the anterior commissure. This moderate level of GAD immunofluo- rescence is slightly greater than in the caudate-putamen and nucleus accumbens, but a relatively sharp border is identifiable between the ventral pallidum and the less intensely stained ventral striatal areas.

The band of ventral pallidal GAD immunofluorescence widens caudally and becomes slightly less intense as it extends underneath the temporal limb of the anterior commissure (Fig. $5 G$ ). Still more caudally, the ventral pallidal GAD staining is continuous with the main portion of the globus pallidus. At this level, the ventral portion of the tubercle still has GAD staining in the polymorph layer, but it is less intense. There is an 
obvious drop-off in intensity where the horizontal limb of the diagonal band intervenes from the medial side. This delineation of the ventral pallidum coincides essentially with the recent description by Switzer et al. (1982) and Haber and Nauta (1983).

Retrograde tracer experiments. We studied the distribution of labeled cells in the forebrain using the GADstaining pallidal system as a point of reference. The results of this study are exemplified by two experiments, rats 83035 and 83076 . The pressure injection of R-SITS in 83035 included most of the MD with more prominent medial involvement (Fig. 1), whereas the FB injection site of 83076 , in which the tracer was implanted by the angular approach from the opposite side, was considerably smaller and confined to the centromedial portion of the MD (Fig. 2). Although the number of labeled cells is much higher in 83035 , which is presented first, the distribution patterns are remarkably similar for the two experiments and are in good agreement with our other MD injections.

Most rostrally, medium-sized TP cells are seen in the frontal pole of the cortex in layers IV to VI. Moving caudally, the anterior extension of the corpus callosum separates these cells into a more dorsomedial group and a ventrolateral group corresponding to the lateral orbital cortex (Krettek and Price, 1977a, b) (Fig. 5, $A$ and $B$ ). Further caudally, where the claustrum appears, the dorsomedial TP cells appear in the deep layers of the cingulate cortex and extend caudally to the mid-thalamic level. The ventrolateral group largely caps the claustrum superficially in the ventral and posterior agranular insular cortex (Krettek and Price, 1977a, b) (Fig. 5, C to $H$ ), and a few TP cells underlie the structure. This group also fades at the mid-thalamic level, but scattered cells persist further caudally. Contralateral TP neurons appear at apparently less than $50 \%$ of the ispilateral quantity for both the dorsomedial and ventrolateral groups. None of the contralateral or ipsilateral TP cells was GAD-positive.

An occasional GAD-negative fluorescent TP cell is seen in the ipsilateral anterior olfactory nucleus, especially in the lateral transition area (de Olmos et al., 1978). These larger cells become more numerous in the rostral POC where they are scattered in the deep polymorph layer (Figs. 3 and $5, B$ to $H$ ). When the olfactory tubercle appears, some TP cells in the POC seem to delineate the border, often residing alongside the strongly positive GAD fibers in the ventral pallidum. By the level of the anterior amygdala, only a few TP cells are seen in the POC. The POC cells are not GAD-positive.

In the olfactory tubercle numerous larger TP cells are in close proximity to the smaller granular cells of the islands of Calleja (Figs. 5, $B$ to $G$, and 6), either on the dorsal surface of or, less often, within the island hiluses. Other similar TP cells are located between the islands in the dense GAD fiber system or within the GAD "fingers" projecting ventrally into the tubercle. Frequent scattered TP cells are present in the deep polymorph layer of the tubercle, but always in association with strongly GAD-positive areas characteristic of the ventral pallidum; none is found in the ventral striatum or fundus of the striatum. Often it is possible to identify TP cells whose cell body and proximal dendrites are completely lined with GAD-like immunoreactivity. However, it is difficult to differentiate between a GAD-staining or GAD-surrounded TP cell in the midst of the heaviest staining portions of the ventral pallidum. Occasionally, an R-SITS-positive fiber in a colchicine-treated rat appears stained for GAD, and, exceptionally, this fiber can be traced to a GAD-positive cell. However, we should emphasize that the presence of cells that are both tracerand GAD-positive is difficult to determine in this area because of the dense synaptic input by GAD-containing terminals.

Tracer-positive cells are also located in the ventral portion of the vertical limb of the diagonal band (NVDB) (Fig. 5, D and $E$ ). Some are also found on its cdge and appear largely within extensions of the ventral pallidum as suggested by heavy GAD-positive staining. Scattered TP cells are found within the vertical limb caudally, especially in the ventral portions.

Further caudally, tracer-positive cells in the ventral pallidum are in continuity with scattered cells in the dorsal part of the globus pallidus (Fig. $5 H$ ). Also, ТP cells extend into the horizontal limb of the diagonal band (NHDB, Fig. 5H). These cells are smaller and more rounded than those in the pallidum. A slight gap of both decreased anti-GAD fluorescence and TP cells exists between the NHDB and the pallidal system as they diverge further caudally.

At the level of the thalamic reticular nucleus, numerous TP cells are in the lateral and dorsal hypothalamic areas and reticular thalamus (data not shown). The density of TP cells in the reticular nucleus is very high, and many of these cells counterstained for GAD.

The ipsilateral amygdala has occasional TP cells in the cortical, medial, and basolateral divisions, and, rarely, elsewhere. Contralaterally, TP cells are seen only occasionally in the ventral pallidum, POC, nuclei of the diagonal band, and lateral hypothalamus in the above pattern. The two rats with injections of NY into the olfactory bulb and FB into the ipsilateral MD had no double-labeled cells.

The distribution of TP cells from rat 83076 is illustrated in Figure 7. This angular FB injection spared the ipsilateral structures overlying the $\mathrm{MD}$ as well as the contralateral habenula and stria medullaris as witnessed by the absence of staining along the track and by the rare contralateral TP cells (data not shown). This small injection recapitulated the findings illustrated above by the rat 83035 . Furthermore, the AChE counterstaining demonstrates that striatal areas do not contain TP cells.

In another rat, the injection was centered within the paraventricular nucleus (approached at a $26^{\circ}$ angle) and minimally encroached upon the medial aspect of the MD not traversed by the tract. Ipsilateral to that MD, only a few TP cells are in the tubercle and primary olfactory and cingulate cortices, while the lateral orbital and ventral agranular insular cortical cell groups are prominently labeled. These latter cell groups may have been labeled by the MD contamination. Labeled cells are also prominent bilaterally in the lateral and medial preoptic hypothalamic areas, suprachiasmatic nuclei, dorsomedial hypothalamic nuclei (although much less in the central 
A
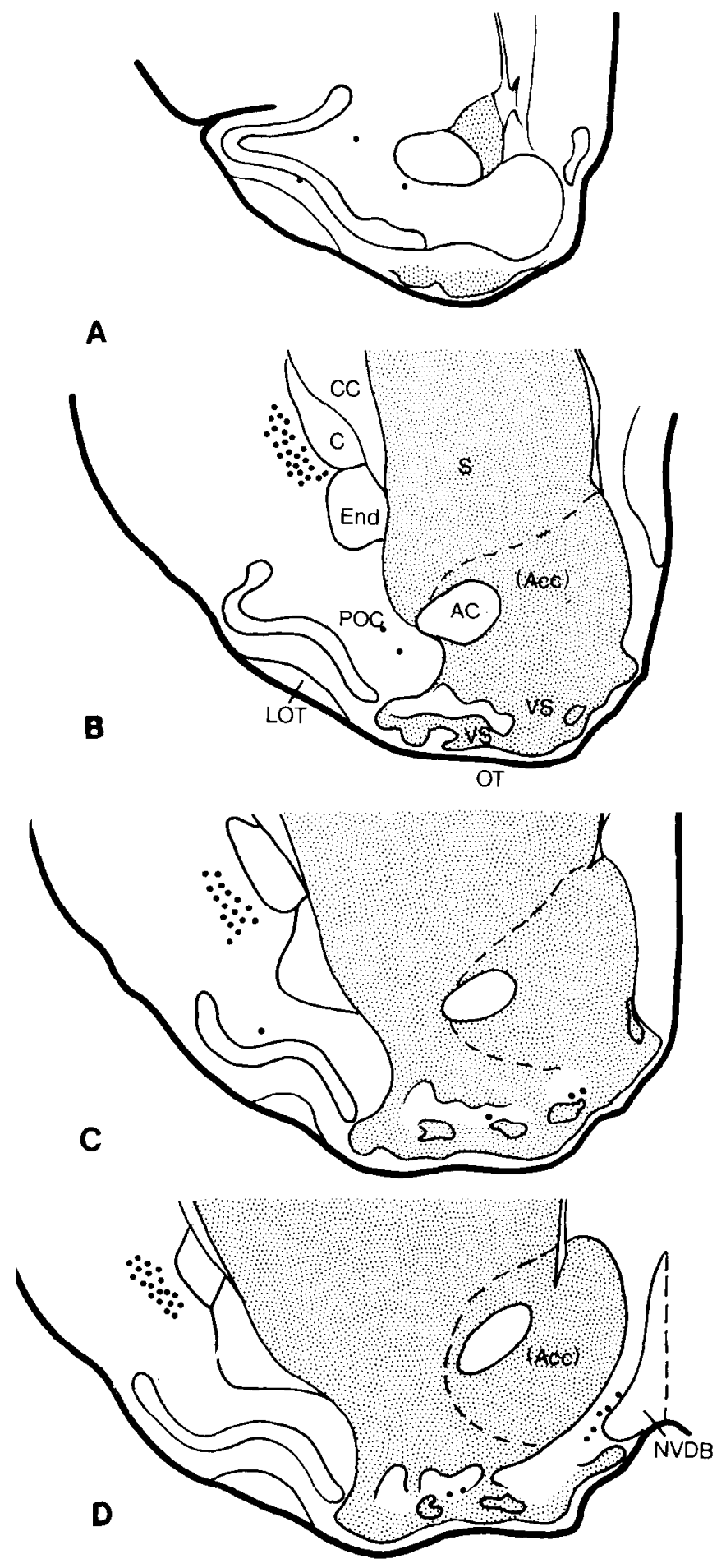
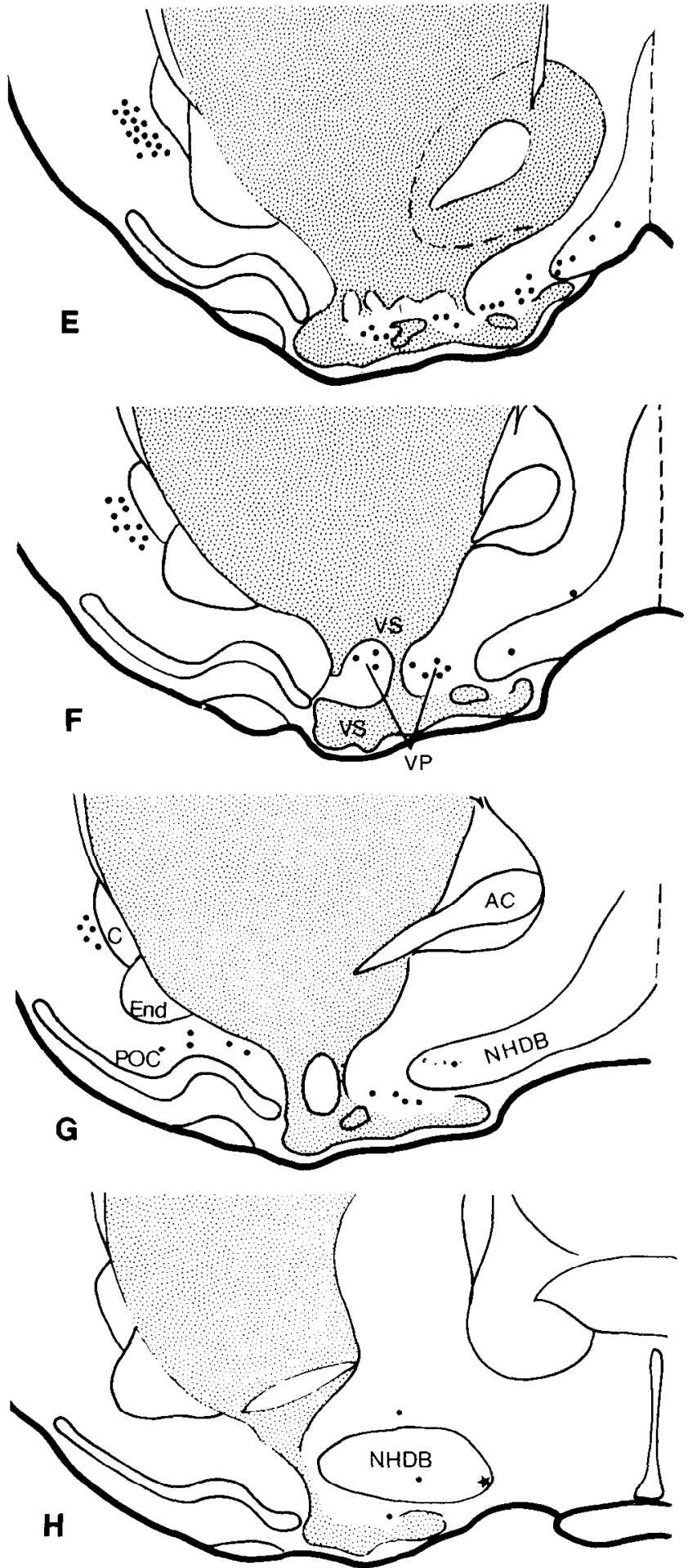

Figure 7. Diagrams of coronal sections from rat 83076 illustrating distribution of TP cells in relation to striatal areas as demonstrated by AChE counterstaining. Other nonstriatal AChE-stained areas, such as NVDB, are not shaded in order to emphasize the complementarity between striatal AChE and pallidal GAD areas (Fig. 5). Pallidal areas do not stain for AChE. The star in $H$ indicates a TP cell which also stained for AChE.

portion), arcuate nuclei, gemini nuclei, and zona incerta. In fact, nearly the entire remaining hypothalamus contains scattered TP cells. This injection apparently spares the terminals of the reticular thalamic input. Similar injections which included the paraventricular nucleus (PVN) and also the dorsomedial portion of the MD result in additional TP cells in the olfactory tubercle and POC as described above. Again, cingulate cortex TP cells are scarce.

Another control FB injection was located within the overlying dorsal hippocampus with an extensive deposit of tracer along the pipette track in the dorsal cingulate 
cortex. No TP cells are observed in the olfactory tubercle or POC. Numerous TP cells are located in the NVDB. These cells segregate into ventral and dorsal groups caudally. The TP cells in the ventral portion overlap the distribution produced by MD injections, although many fewer are seen in the latter cases. Conversely, only a few TP cells are in the medial aspect of the subcommissural ventral pallidum and NHDB, whereas MD injections result in numerous TP cells in these areas. Even fewer TP cells are observed in the lateral hypothalamic area. No TP cells are seen in the agranular insular cortex; instead, they are within the claustrum itself.

An injection of FB was also placed into the overlying habenula, stria medullaris, and hippocampus. The MD was spared, but the distribution of TP cells overlaps extensively in the forebrain with that observed after MD injections. The number of TP cells is less in the olfactory tubercle and pallidal system, and more are in the medial NHDB and in the NVDB than after MD injections. An occasional TP cell is seen in the deep rhinal cortex.

\section{Discussion}

We have described the location of cells within the basal forebrain projecting to the MD. Our results agree in general with those described previously (see references cited in the introduction). However, by using a combination of immunohistochemistry and retrograde tracer techniques, we have been able to locate labeled cells precisely with respect to the ventral striatal and pallidal systems. The methods used were important in reliably defining this projection, and, therefore, a few comments concerning the methods are necessary before discussing our results.

The fluorescent retrograde tracers are more reliable and appear to be at least as sensitive as other retrograde tracing methods, including the horseradish peroxidase techniques. The injection of retrograde tracers carries the probability of contamination of adjacent structures. Several of our precautions have minimized this problem. First, we used R-SI'l'S which may obviate the fibers-ofpassage dilemma. Obviously, more studies are needed in this area, but our limited observations of corpus callosum injections confirm the findings of Schmued and Swanson (1982) that R-SITS is not taken up by fibers-of-passage. Whether certain fibers exist which can take up R-SITS and transport the compound is unknown. Second, those injections with no or trace contamination of habenula or stria medullaris were principally considered in defining basal forebrain projections. The injections made at $26^{\circ}$ from the horizontal enabled us to avoid the overlying structures as well. Observations of other animals revealed that habenular or stria medullaris contamination did not distort the distribution very much except for the presence of a large number of TP cells within the entopeduncular nucleus. This is consistent with the findings of Herkenham and Nauta (1977), who studied the origin of the afferent habenular concentrations following HRP injections in various parts of the habenular complex. Although they found a small number of cells in the nucleus of the diagonal band and the most dorsal part of the ventral pallidum, no cells were labeled in the olfac- tory tubercle or ventral pallidal regions unless stria medullaris fibers had been directly involved in the injection. Furthermore, both degeneration studies (Leonard and Scott, 1971; Heimer, 1972) and the HRP study by Herkenham and Nauta (1977) indicate that the POC does not project to the habenula. There may have been minimal PVN contamination by our MD injections since both PVN and MD injections result in TP cells in the lateral hypothalamus. However, as is the case with insular cortex TP cells after PVN injections, the lateral hypothalamic TP cells may also represent MD contamination during PVN injections. Control injections into the cingulate cortex overlying the MD do not label cells in basal forebrain areas projecting to MD. Furthermore, hippocampal injections produced only minimal overlapping distributions in the NVDB, medial NHDB, and subcommissural ventral pallidum and no TP cells in the olfactory tubercle or POC.

Ventral pallidal projections to $M D$. The notion that the striatum and the globus pallidus of the rat extend in a rostral and ventral direction toward the surface of the brain in the region of the olfactory tubercle (Heimer and Wilson, 1975; Heimer, 1978) has been well substantiated with the aid of hodological methods and various histochemical techniques (Switzer and Hill, 1979; Newman and Winans, 1980; Haber and Nauta, 1981, 1983; Haber et al., 1982; Switzer et al., 1982; Zaborsky et al., 1982; Fallon et al., 1983). Striatal markers like dopamine and AChE (Fallon et al., 1983) demonstrate convincingly that the caudate-putamen and the nucleus accumbens are continuous with ventral striatal cell territories in the olfactory tubercle via "striatal cell bridges" (Fig. 27 in Heimer, 1978). Furthermore, pallidal markers (e.g., iron, enkephalin, GAD, and substance P) leave little doubt that the ventral striatal areas are accompanied in their entire extent by a similar rostroventral extension of the globus pallidus, which includes a large part of what has traditionally been referred to as the anterior part of the substantia innominata. The tubercle part of the ventral pallidum is characterized by a number of finger-like protrusions into the polymorph layer of the olfactory tubercle (Switzer and Hill, 1979; Switzer et al., 1982; Ilaber and Nauta, 1983), and these finger-like extensions usually reach the hilus of an island of Calleja (Fallon et al., 1983; see also Fig. 6).

Preliminary studies in our laboratory (Zaborszky et al., 1982) indicate that areas of strong GAD-like immunoreactivity in the basal forebrain of the rat correspond closely to regions which have been identified as ventral pallidum on the basis of high affinity for iron (Switzer et al., 1982) or substance $P$ and enkephalin immunoreactivity (Switzer et al., 1982; Haber and Nauta, 1983). Therefore, GAD was used as a pallidal marker in this study and the locations of the retrogradely labeled cells, which appeared as a result of MD injections, were determined with reference to the strong GAD-like immunoreactivity. The close correspondence between TP cells and GAD-rich pallidal areas were remarkable, especially in the olfactory tubercle, where practically every MDprojecting cell was located within areas identified as ventral pallidum. Many of the TP cells were located within the hiluses of the islands of Calleja or on their 
perimeters. This is in accord with the work of Fallon (1983), who showed that medium and large cells associated with the islands project to the MD and are heavily innervated by GAD-containing axons.

TP cells are also abundant in the deeper portions of the ventral pallidum, i.e., deep to the olfactory tubercle; and such cells, like the ones in the pallidal parts of the olfactory tubercle, are often heavily invested by GADpositive puncta and fibers. These cells are particularly prominent in those portions of the ventral pallidum that receive projections from the striatal parts of the olfactory tubercle (unpublished observations). The more dorsal or subcommissural part of the ventral pallidum (Fig. $5 \mathrm{H}$ ), which receives its striatal projection primarily from the nucleus accumbens (Wilson, 1972; Swanson and Cowan, 1976; Zaborszky et al., 1982), contains fewer TP cells.

Our attempts to determine the transmitter of the ventral pallidal-MD projection were unsuccessful. GABA is thought to be the transmitter contained in cells projecting to the ventral thalamus from the more dorsal globus pallidus (Penney and Young, 1981; Pan et al., 1983). GAD labeling in many TP cells was ambiguous since the great density of GAD activity about these cells prevented us from distinguishing between double-labeled and simply synaptically contacted cells. Other unpublished observations in our laboratory suggest that neither enkephalin- nor substance $\mathrm{P}$-containing cells project to the $\mathrm{MD}$ in any appreciable degree, although neurotensin-containing cells in the POC appear to project there. Further experiments in thin sections are in progress to determine the projecting neurotransmitter(s).

Fallon (1983) suggested that the MD-projecting cells in the immediate surround of the islands of Calleja contain AChE. However, in our case 83076 we were unable to confirm that any of the MD-projecting cells in the ventral pallidum, including those in the tubercle, are cholinesterase-positive. Clearly, more studies are needed to settle the question as to whether the MD projecting cells are cholinergic, cholinoceptive, or neither. If the situation in the ventral pallidum is analogous to that of the dorsal pallidum, one would not expect this pallidothalamic projection to be cholinergic.

The fact that the TP cells in the region of the tubercle following injection into MD are located in strongly GADpositive areas recognized as ventral pallidum strengthens the concept that the olfactory tubercle actually is an integral part of a ventral striato-pallidal system paralleling the classic striato-pallidal system (Heimer and Wilson, 1975; Heimer, 1978; Haber et al., 1982). The latter projects, in part, to the ventral thalamic cell group (for review, see Carpenter, 1976; Graybiel and Ragsdale, 1979), while the former projects to the thalamus as well. At this time, it is not possible to identify subdivisions within the ventral pallidum that match the divisions of the dorsal pallidal complex (i.e., the globus pallidus and the entopeduncular nucleus). However, both elements may be represented since the ventral pallidum in the rat is directly continuous with the globus pallidus (corresponding to the external segment in primates), while the thalamic projection is more characteristic of the entopeduncular nucleus.

Although the function of the ventral striato-pallidal system remains unknown at the present time, suggestions have been made that this is an area of limbic input influencing motor activity (Mogenson et al., 1980; Newman and Winans, 1980; Heimer et al., 1982).

The olfactory tubercle as an integral part of the corpus striatum. The nature of the olfactory tubercle has long been a matter of debate, and the subject has been reviewed recently by several investigators including one of the present authors (Pigache, 1970; Stephan, 1975; Heimer, 1978). The apparent lamination of the superficial cells of the olfactory tubercle and the fact that olfactory bulb projection fibers reach most of the tubercle, at least in macrosmatic mammals, have no doubt contributed to the rather widespread tendency to include the tubercle as part of the olfactory cortex. However, the recent descriptions of the ventral striatum and ventral pallidum (Switzer et al., 1982; Haber and Nauta, 1983; Fallon et al., 1983) have emphasized the need for a re-evaluation of the nature of the rat olfactory tubercle, and the results obtained in this study only underscore the distinction between the primary olfactory cortex (prepiriform cortex) and the olfactory tubercle.

Although it is true that the superficial appearance of the olfactory tubercle is reminiscent of a cortical structure, especially in macrosmatic mammals, it is also true that the degree of lamination varies between different species, or even from one region of the tubercle to another in the same species. It is also evident that the olfactory bulb projects to the superficial layer of the entire olfactory tubercle in commonly used macrosmatic laboratory animals such as rat, rabbit, and hamster (Heimer, 1968; Price, 1973; Davis et al., 1978). However, when comparing the amount of direct olfactory bulb input to the tubercle and the primary olfactory cortex, the difference between the two regions is striking, in that the olfactory tubercle receives a much smaller input than the POC. But it is above all the large number of qualitative anatomical and histochemical differences that distinguishes the tubercle from the primary olfactory cortex.

First, the primary olfactory cortex in the rat is characterized by a massive centrifugal projection system to the olfactory bulb (e.g., de Olmos et al., 1978; Haberly and Price, 1978). No comparable centrifugal pathway to the bulb takes its origin in the olfactory tubercle, even if some cells deep to the tubercle are labeled following HRP injections in the olfactory bulb. However, those cells probably represent a rostral extension of the nucleus of the horizontal limb of the diagonal band (de Olmos et al., 1978).

Second, although the primary olfactory cortex sends a significant projection to the olfactory tubercle (Haberly and Price, 1978; Luskin and Price, 1983), there is no reciprocal associative projection from the tubercle to the olfactory cortex as would be expected if the olfactory tubercle were an integral part of the olfactory cortex. The absence of a reciprocal projection from the tubercle to the olfactory cortex speaks in favor of including the olfactory tubercle in the concept of the ventral striatopallidal system, in which case the olfactory cortex projection to the tubercle would represent a cortico-striatal projection (Fig. 8).

Third, in addition to the input from the olfactory bulb 


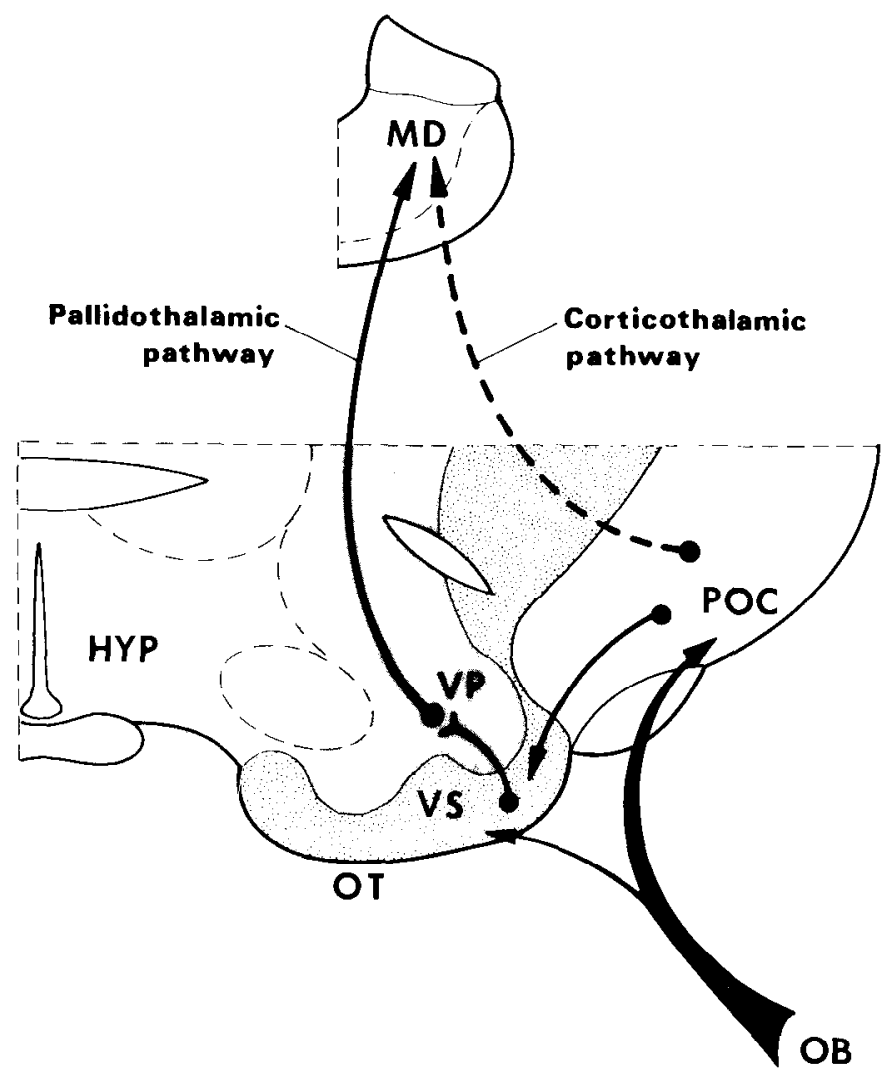

Figure 8. Schematic diagram illustrating ventral pallidothalamic and olfactory corticothalamic pathways to MD. Further details are discussed in the text.

and the primary olfactory cortex, the olfactory tubercle receives a significant dopaminergic input from the midbrain (Fuxe, 1965; Ungerstedt, 1971; Hedreen and Chalmers, 1972) and another input from intralaminar thalamic nuclei (Haberly and Price, 1978; Newman and Winans, 1980). This triad of cortical, midbrain dopaminergic, and intralaminar thalamic afferents, which characterizes the striatum in general, was originally used as an argument for including the medium-sized cell territories of the tubercle in the concept of the ventral striatum (Heimer and Wilson, 1975). Admittedly, the fact that the olfactory tubercle receives a direct input from the olfactory bulb would seem to indicate that part of the ventral striatum is under direct influence of the olfactory system, which would be exceptional. But the olfactory system is, after all, a maverick in more than one sense. For instance, it is the only sensory system that reaches the cerebral cortex without a relay in the thalamus. Furthermore, it is not unreasonable to expect some significant differences in connectivity between different parts of the striato-pallidal system. Indeed, striking differences have already been discovered in regard to the amygdalo-striatal projections which reach most of the striatum except the anterior dorsolateral quadrant (Kelley et al., 1982).

Fourth, although basal forebrain projections to the MD originate both in the tubercle and the POC, the results obtained in this study clearly indicate that the two projection systems are very different in nature in spite of the fact that they both terminate in the central, "olfactory"-related part of the MD. The MD-projecting cells within the olfactory tubercle have been recognized as the origin for a pallido-thalamic projection (Fig. 8) primarily because its cells of origin are almost completely located within areas that we and others (Switzer et al., 1982; Haber and Nauta, 1983) have identified as ventral pallidum on the basis of cytoarchitectural and histochemical characteristics. The MD-projecting cells in the primary olfactory cortex, on the other hand, must certainly be considered to represent a cortico-thalamic projection system. The messages that these two "olfactory"related systems are transmitting to the MD are likely to be of different nature, if for no other reason that the MD-projecting cells in the ventral pallidum receive a pattern of afferent connections that is very different from the input to the MD-projecting cells in the primary olfactory cortex. These fundamental anatomical differences are likely to be of great significance in whatever physiological and behavioral mechanism the two "olfactory"-related MD projections are involved.

Last, the neurochemistry of the olfactory tubercle is reminiscent of that in the rest of the striatum (Krieger, 1981), and recent histochemical studies (Switzer et al., 1982; Fallon et al., 1983; Haber and Nauta, 1983) clearly demonstrate that not only the striatum but also the globus pallidus extend into and form part of the olfactory tubercle as traditionally defined. If, in addition, the islands of Calleja and their proposed relation to an endocrine-related striato-pallidal system are taken into consideration (Ribak and Fallon, 1982; Fallon, 1983; Fallon, et al., 1983), it would seem that little is gained by continuing to perceive of the olfactory tubercle as part of the primary olfactory cortex, or even as a modified type of olfactory cortex. Whatever the functions of the olfactory tubercle may be, it seems reasonable to suggest that the tubercle is performing those functions by a neuronal machinery that is very much striato-pallidal in character. As already indicated, however, the most ventral part of the striato-pallidal system, i.e., that part which is most closely identified with the olfactory tubercle, does have several unique features which set it apart from the rest of the corpus striatum.

Note added in proof. While this paper was in press, Payne et al. (1983) published a paper in which they reported that "R-SITS" identical to that used in the present study contained two active contaminants. The first is retrogradely transported, the second is a neurotoxin; neither is the stilbene derivative "SITS."

\section{References}

Akert, K., and K. Hartmann-Von Monakow (1980) Relationships of precentral, premotor and prefrontal cortex to the mediodorsal and intralaminar nuclei of the monkey thalamus. Acta Neurobiol. Exp. (Warsz.) 40: 7-25.

Alheid, G. F., and J. Carlsen (1982) Small injections of fluorescent tracers by iontophoresis or chronic implantation of micropipettes. Brain Res. 235: 174-178.

Benjamin, R. M., J. C. Jackson, G. T. Golden, and C. H. K. West (1982) Sources of olfactory input to opossum mediodorsal nucleus identified by horseradish peroxidase and autoradiographic methods. J. Comp. Neurol. 207: 358-368.

Carpenter, M. B. (1976) Anatomy of the basal ganglia and related nuclei: A review. Adv. Neurol. 14: 7-48.

Davis, B. J., F. Macrides, W. M. Youngs, S. P. Schneider, and D. L. Rosene (1978) Efferents and centrifugal afferents of 
the main and accessory olfactory bulbs in the hamster. Brain Res. Bull. 3: 59-72.

de Olmos, J., H. Hardy, and L. Heimer (1978) The afferent connections of the main and the accessory olfactory bulb formations in the rat: An experimental HRP-study. J. Comp. Neurol. 181: 213-244.

Fallon, J. H. (1983) The islands of Calleja complex of rat basal forebrain. II. Connections of medium and large sized cells. Brain Res. Bull. 10: 775-793.

Fallon, J. H., S. E. Loughlin, and C. E. Ribak (1983) The islands of Calleja complex of rat basal forebrain. III. Histochemical evidence for a striatopallidal system. J. Comp. Neurol. 218: 91-120.

Fonnum, F., I. Grofova, E. Rinvik, J. Storm-Mathisen, and F. Waldberg (1974) Origin and distribution of glutamate decarboxylase in substantia nigra of the cat. Brain Res. 71: 77-92.

Fonnum, F., Z. Gottesfeld, and I. Grofova (1978) Distribution of glutamate decarboxylase, choline acetyltransferase, and aromatic amino acid decarboxylase in the basal ganglia of normal and operated rats. Evidence for striatopallidal, striatoentopeduncular and striatonigral GABAergic fibers. Brain Res. 143: 125-138.

Fuxe, K. (1965) Evidence for the existence of monoamine neurons in the central nervous system. IV. Distribution of monoamine nerve terminals in, the central nervous system. Acta Physiol. Scand. Suppl. 247: 39-85.

Goldschmidt, R. B., and L. Heimer (1980) The rat olfactory tubercle: Its connections and relation to the strio-pallidal system. Soc. Neurosci. Abstr. 6. 271.

Graybiel, A. M., and C. W. Ragsdale, Jr. (1979) Fiber connections of the basal ganglia. Prog. Brain Res. 51: 239-283.

Groenewegen, H. J., and W. J. H. Nauta (1982) Afferent and efferent connections of the mediodorsal thalamic nucleus in the rat. Neurosci. Lett. Suppl. 10: 217.

Guillery, R. W. (1959) Afferent fibres to the dorso-medial thalamic nucleus in the cat. J. Anat. 93: 403-419.

Haber, S. N., and W. J. H. Nauta (1981) Substance P, but not enkephalin, immunoreactivity distinguishes ventral from dorsal pallidum. Soc. Neurosci. Abstr. 7: 916.

Haber, S. N., and W. J. H. Nauta (1983) Ramifications of the globus pallidus in the rat as indicated by patterns of immunohistochemistry. Neuroscience 9: 245-260.

Haber, S. N., H. J. Groenewegen, and W. J. H. Nauta (1982) Efferent connections of the ventral pallidum in the rat. Soc. Neurosci. Abstr. 8: 169.

Haberly, L. B., and J. L. Price (1978) Association and commissural fiber systems of the olfactory cortex of the rat. I. Systems originating in the piriform cortex and adjacent areas. J. Comp. Neurol. 178: 711-740.

Hardy, H., L. Heimer, R. Switzer, and D. Watkins (1976) Simultaneous demonstration of horseradish peroxidase and acetylcholinesterase. Neurosci. Lett. 3: 1-5.

Hedreen, J. C., and J. P. Chalmers (1972) Neuronal degeneration in rat brain induced by 6 -hydroxydopamine: A histological and biochemical study. Brain Res. 47: 1-36.

Heimer, L. (1968) Synaptic distribution of centripetal and centrifugal nerve fibres in the olfactory system of the rat. J. Anat. 103: 413-432.

Heimer, L. (1972) The olfactory connections of the diencephalon in the rat. Brain Behav. Evol. 6: 484-523.

Heimer, L. (1975) Olfactory projections to the diencephalon. In Anatomical Neuroendocrinology, W. E. Stumpf and L. D. Grant, eds., pp. 30-39, S. Karger, New York.

Heimer, L. (1978) The olfactory cortex and the ventral striatum. In Limbic Mechanisms: The Continuing Evolution of the Limbic System Concept, K. E. Livingston and O. Hornykiewicz, eds., pp. 95-187, Plenum Press, New York.

Heimer, L., and R. D. Wilson (1975) The subcortical projections of the allocortex: Similarities in the neural associations of the hippocampus, the piriform cortex and the neocortex. In Golgi Centennial Symposium Proceedings, M. Santini, ed., pp. 177-193, Raven Press, New York.

Heimer, L., R. D. Switzer, and G. W. Van Hoesen (1982) Ventral striatum and ventral pallidum. Component of the motor system? Trends Neurosci. 5: 83-87.

Herkenham, M., and W. J. H. Nauta (1977) Afferent connections of the habenular nuclei in the rat. A horseradish peroxidase study, with a note on the fiber-of-passage problem. J. Comp. Neurol. 173: 123-146.

Inagaki, S., Y. Kubota, K. Shinoda, Y. Kawai, and M. Tohyama (1983) Neurotensin-containing pathway from the endopiriform nucleus and the adjacent prepiriform cortex to the dorsomedial thalamic nucleus in the rat. Brain Res. 260: 143146.

Kelley, A. E., V. B. Domesick, and W. J. H. Nauta (1982) The amygdalostriatal projection in the rat. An anatomical study by anterograde and retrograde tracing methods. Neuroscience $7: 615-630$.

Krettek, J. E., and J. L. Price (1974) A direct input from the amygdala to the thalamus and the cerebral cortex. Brain Res. 67: $169-174$.

Krettek, J. E., and J. L. Price (1977a) The cortical projections of the mediodorsal nucleus and adjacent thalamic nuclei in the rat. J. Comp. Neurol. 171: 157-192.

Krettek, J. E., and J. L. Price (1977b) Projections from the amygdaloid complex to the cerebral cortex and thalamus in the rat and cat. J. Comp. Neurol. 172: 687-722.

Krieger, N. R. (1981) The neurochemistry of the olfactory tubercle. In Biochemistry of Tuste and Olfaction, R. Cagan and M. R. Kare, eds., pp. 417-441, Academic Press, New York.

Leonard, C. M. (1969) The prefrontal cortex of the rat. I. Cortical projection of the mediodorsal nucleus. II. Efferent connections. Brain Res. 12: 321-343.

Leonard, C. M., and J. W. Scott (1971) Origin and distribution of amygdalofugal pathways in the rat: An experimental neuroanatomical study. J. Comp. Neurol. 141: 313-330.

Luskin, M. B., and J. L. Price (1983) The topographic organization of associational fibers of the olfactory system in the rat, including centrifugal fibers in the olfactory bulb. J. Comp. Neurol. 216: 264-291.

Markowitsch, H. J., E. Irle, and M. Streicher (1982) The thalamic mediodorsal nucleus receives input from thalamic and cortical regions related to vision. Neurosci. Lett. 32: 131136.

McLaughlin, B. J., J. G. Wood, K. Saito, R. Barber, J. E. Vaughn, E. Roberts, and J. -Y. Wu (1974) The fine structural localization of glutamate decarboxylase in synaptic terminals of rodent cerebellum. Brain Res. 76: 377-391.

Mogenson, G. J., D. L. Jones, and C.-Y. Yim (1980) From motivation to action: Functional interface between the limbic system and motor system. Prog. Neurobiol. 14: 69-97.

Nagy, J. I., D. A. Carter, and H. C. Fibiger (1978) Anterior striatal projections to the globus pallidus, entopeduncular nucleus and substantia nigra in the rat. The GABA connection. Brain Res. 158: 15-29.

Nauta, W. J. H. (1961) Fibre degeneration following lesions of the amygdaloid complex in the monkey. J. Anat. (Lond.) 95: $515-531$

Newman, R., and S. S. Winans (1980) An experimental study of the ventral striatum of the golden hamster. II. Neuronal connections of the olfactory tubercle. J. Comp. Neurol. 191: $193-212$.

Oertel, W. H., D. E. Schmechel, M. L. Tappaz, and I. J. Kopin (1981) Production of a specific antiserum to rat brain glutamic acid decarboxylase by injection of an antigen-antibody complex. Neuroscience 6: 2689-2700.

Oertel, W. H., E. Mugnaini, D. E. Schmechel, M. L. Tappaz, 
and I. J. Kopin (1982) The immunocytochemical demonstration of gamma-aminobutyric acid-ergic neurons-methods and application. In Cytochemical Methods in Neuroanatomy, V. Chan-Palay and S. L. Palay, eds., pp. 297-329, Alan R. Liss, Inc., New York.

Pan, H. S., K. A. Freg, A. B. Young, and J. B. Penney, Jr. (1983) Changes in $\left[{ }^{3} \mathrm{H}\right]$-muscimol binding in substantia nigra, entopeduncular nucleus, globus pallidus, and thalamus after striatal lesions as demonstrated by quantitative receptor autoradiography. J. Neurosci. 3: 1189-1198.

Payne, J. N., I. N. C. Lawes, G. B. Proctor, and R. W. Harovin (1983) Variation between different samples of SITS with respect to axonal transport and toxicity. Neurosci. Lett. 42: $229-234$.

Penney, J. B., Jr., and A. B. Young (1981) GABA as the pallidothalamic neurotransmitter: Implications for basal ganglia function. Brain Res. 207: 195-199.

Perez de la Mora, M., L. D. Possani, R. Tapia, L. Teran, R. Palacios, K. Fuxe, T. Hökfelt, and A. Ljungdahl (1981) Demonstration of central gamma-aminobutyrate-containing nerve terminals by means of antibodies against glutamate decarboxylase. Neuroscience $6: 875-895$.

Pigache, R. M. (1970) The anatomy of "paleocortex." A critical review. Ergeb. Anat. Entwickl. Gesch. 43: 3-62.

Powell, T. P. S., W. M. Cowan, and G. Raisman (1965) The central olfactory connexions. J. Anat. 99: 791-813.

Price, J. L. (1973) An autoradiographic study of complementary laminar patterns of termination of afferent fibers to the olfactory cortex. J. Comp. Neurol. 150: 87-108.

Price, J. L., and B. M. Slotnick (1983) Dual olfactory representation in the rat thalamus: An anatomical and electrophysiological study. J. Comp. Neurol. 215: 63-77.

Ribak, C. E. (1981) The GABAergic neurons of the extrapyramidal system as revealed by immunocytochemistry. In GABA and the Basal Ganglia, G. Di Chiara and G. L. Gessa, eds., pp. 23-36, Raven Press, New York.

Ribak, C. E., and J. H. Fallon (1982) The island of Calieja complex of rat basal forebrain. I. Light and electron microscopic observations. J. Comp. Neurol. 205: 207-218.

Ribak, C. E., J. E. Vaughn, and E. Roberts (1979) The GABA neurons and their axon terminals in rat corpus striatum as demonstrated by GAD immunocytochemistry. J. Comp. Neurol. 187: 261-284.

Schmued, L. C., and L. W. Swanson (1982) SITS: A covalently bound fluorescent retrograde tracer that does not appear to be taken up by fibers-of-passage. Brain Res. 249: 137-141.

Schmued, L. C., L. W. Swanson, and P. E. Sawchenko (1982) Some fluorescent counterstains for neuroanatomical studies. J. Histochem. Cytochem. 30: 123-128.

Scott, J. W., and C. M. Leonard (1971) The olfactory connections of the lateral hypothalamus in the rat, mouse and hamster. J. Comp. Neurol. 141: 331-344.

Siegel, A., T. Fukushima, R. Meibach, L. Burke, H. Edinger, and S. Weiner (1977) The origin of the afferent supply to the mediodorsal thalamic nucleus: Enhancement of HRP transport by selective lesions. Brain Res. 135: 11-23.

Stephan, H. (1975) Allocortex. In Handbuch der mikroskopischen Anatomie des Menschen, Springer-Verlag, Berlin.

Swanson, L. W., and W. M. Cowan (1976) A note on the connections and development of the nucleus accumbens. Brain Res. 92: 324-330.

Switzer, R. C., and J. M. Hill (1979) Globus pallidus component in the olfactory tubercle: Evidence based on iron distribution. Soc. Neurosci. Abstr. 5: 79 .

Switzer, R. C., III, J. Hill, and L. Heimer (1982) The globus pallidus and its rostroventral extension into the olfactory tubercle of the rat: A cyto- and chemoarchitectural study. Neuroscience 7: 1891-1904.

Ungerstedt, U. (1971) Stereotaxic mapping of the monoamine pathways in the rat brain. Acta Physiol. Scand. Suppl. 367: $1-48$.

Walaas, I., and F. Fonnum (1979) The distribution and origin of glutamate decarboxylase and choline acetyltransferase in ventral pallidum and other basal forebrain regions. Brain Res. 177: 325-336.

Wilson, R. D. (1972) Efferent connections of the nucleus accumbens in the rat. Master's thesis, Massachusetts Institute of Technology, Cambridge.

Wu, J.-Y., C.-T. Lin, C. Brandon, T.-S. Chan, H. Möhler, and J. G. Richards (1982) Regulation and immunocytochemical characterization of glutamic acid decarboxylase. In Cytochemical Methods in Neuroanatomy, V. Chan-Palay and S. L. Palay, eds., pp. 279-296, Alan R. Liss, Inc., New York.

Zaborszky, L., G. F. Alheid, V. E. Alones, W. H. Oertel, D. E. Schmeckel, and L. Heimer (1982) Afferents of the ventral pallidum studied with a combined immunohistochemicalanterograde degeneration method. Soc. Neurosci. Abstr. 8: 218. 